\title{
Implementing a Health Confidence Tool at Time of Discharge
}

\author{
T. Joseph Mattingly II ${ }^{1}$ (D) Khang Nong ${ }^{1}$
}

Published online: 30 October 2018

(c) The Author(s) 2018

\section{Dear Editor,}

Patient engagement has been used broadly to describe interventions designed to improve patient activation, encourage healthy behaviors such as seeking health information or preventive services, and to increase the patient's knowledge, skill, and confidence to manage his or her health [1]. Patient-reported health confidence has been measured as a proxy for constructs such as patient activation and engagement given its relative ease of collection during a routine patient-provider interaction [2]. Higher health confidence scores in primary care settings have been associated with better health outcomes, while lower levels of confidence have been associated with poor outcomes such as unnecessary use of the emergency department [3].

For patients with chronic conditions requiring pharmacotherapy, community pharmacy use is a part of routine care. In 2015, prescription drug utilization made up approximately $10 \%$ of overall health services spending in the United States, and the total number of prescription drugs dispensed on an outpatient basis continues to grow [4]. Low self-efficacy, which captures a patient's feeling of confidence to handle treatment decisions or manage treatment side effects, may be as high as $20 \%$ in disease states such as prostate cancer and in patients with the human immunodeficiency virus (HIV) [5, 6]. For patients with high health confidence, additional counseling at the pharmacy counter may provide little marginal value. This may not be the case for patients unsure about their condition who may still have lingering questions about appropriate disease management. Identifying patients with low levels of self-reported confidence or efficacy may allow for more appropriate allocation of resources and further intervention to prevent poor adherence or other negative outcomes. This

T. Joseph Mattingly II

jmattingly@rx.umaryland.edu

1 University of Maryland School of Pharmacy, 20 North Pine Street, N415, Baltimore, MD 21201, USA research letter summarizes a recent study we conducted that demonstrates how pharmacy technicians can be used to identify patients with low health confidence by incorporating a brief survey instrument into routine medication services.

We identified patients at the time of discharge from an inpatient stay who opted into an existing prescription delivery service from the institution's in-house community pharmacy. Patients who agreed to participate were interviewed by pharmacy technicians in person at the time of discharge and by telephone between 30-45 days post-discharge to determine patient self-reported confidence levels and reasons why patients felt high or low levels of confidence related to managing their health conditions. Confidence levels were rated on a scale of 0-10 using the Wasson and Coleman confidence tool and operationalized as a categorical variable, with "low confidence" defined as any score below 7 [3]. Reasons for confidence scores were captured as open-ended text, imported into NVivo version 12 (QSR International Pty Ltd.), and coded following principles of grounded theory [7]. Themes that emerged were described to identify potential issues from the patient perspective that impacted his or her confidence at discharge. Descriptive statistics were reported for age, confidence scores, and proportion hospitalized within 30 days of discharge. Association between hospitalized/not hospitalized and confidence group was assessed using a Fisher exact or Chi square test.

A total of 200 patients received the initial survey at discharge, and $141(70.5 \%)$ answered and agreed to the postdischarge survey. Reasons for confidence score responses related to the care received during the inpatient stay and quality of discharge instructions, family or social support, health status, or experience with surgery (Table 1). Of the patients who completed the post-discharge survey, 27 (19.1\%) were readmitted within 45 days of discharge. Defining a patient as "low confidence" at discharge categorically as "less than 7" was not related to readmission, but it was significant when defining "low confidence" as "less than 8" on a 10-point scale (Table 2).

This pilot study demonstrated the potential for using the Wasson and Coleman's health confidence tool at the time of 
discharge in an acute care setting and in addition to capturing patient perspectives on factors related to their overall health confidence when leaving the hospital [3]. After leaving the hospital, nearly $30 \%$ of the patients were unable to be reached after three calls, which may limit the usefulness of such a survey if the post-discharge contact is done by telephone. This suggests that different approaches to following patients once they leave the hospital may be needed based on patient contact preference.

We found that confidence scores appeared higher at the time of discharge than what was expected based on previous studies, which may indicate overconfidence or a confounding issue where patients provided a higher confidence score for fear that the provider may not discharge them if they answer truthfully. Baseline proportions of patients providing a self-rating of high health confidence assessed in ambulatory clinics ranged from 45 to $65 \%$ [2]. A longitudinal study of 1047 patients in rural primary care clinics observed over a third of the patients reporting low confidence [8]. Wasson and Coleman suggest scores "less than 7" as a cut-point for low confidence; however, this pilot may suggest that anyone answering "less than 8 " on the survey may be worth evaluating due to risk of readmission [3]. Further evaluation of the 10-point scale for health confidence for this population may be warranted, as the setting of the survey in previous studies has primarily been in ambulatory or primary care practices. While this was a small sample, it may suggest that incorporating a brief two-item survey into the discharge process could potentially identify patients at a higher risk for readmission.

This particular intervention was led by the pharmacy team, but the tool could be implemented by nursing or other staff involved in the discharge process. The authors' institution also qualifies as a 340B covered entity, enabling increased margins from outpatient medication services for patients being discharged to support new interventions that can improve care [9]. The 340B drug pricing program was established in the United States in 1992 to provide significant discounts on outpatient drugs to hospitals and other facilities that provide a significant amount of care to low-income or underserved populations [10]. While this pilot study focused on implementing the survey to identify patients with lowconfidence scores and reasons for that score, the post-appropriate intervention or follow-up action was not assessed. The pharmacy technicians followed standard processes of communicating with other hospital staff related to the medication concierge service. Since this confidence tool has not been validated in a discharge setting, scores did not impact patient care delivery for this pilot.

A lack of social support has been previously identified as a potential predictor for readmission, supporting our study's findings regarding patient-reported confidence [11]. Our
Table 1 Categories of patientreported reasons for confidence responses with verbatim quotes from survey

Table 2 Exploratory statistical tests for readmission rates by different confidence thresholds

\begin{tabular}{|c|c|}
\hline Category & Examples \\
\hline Care received & $\begin{array}{l}\text { "Great hospital staff took care of me." } \\
\text { "I couldn't have asked for a better medical team." }\end{array}$ \\
\hline Family & $\begin{array}{l}\text { "My husband will be taking care of me." } \\
\text { "I have a supportive family and church support." }\end{array}$ \\
\hline Health status & $\begin{array}{l}\text { "I'm still concerned about health challenges and rebuilding } \\
\text { my muscles even though the doctor explained things very } \\
\text { well." } \\
\text { "I've had health issues for } 15 \text { years." }\end{array}$ \\
\hline Instructions & $\begin{array}{l}\text { "Nurse gave great discharge instructions." } \\
\text { "We have good training; good staff instructions for home." }\end{array}$ \\
\hline Support & $\begin{array}{l}\text { "I have extra support at home." } \\
\text { "I got a good support group." }\end{array}$ \\
\hline Surgery & $\begin{array}{l}\text { "This is my 6th surgery and I have plenty of experience." } \\
\text { "I feel better, but I am still undergoing surgery." }\end{array}$ \\
\hline
\end{tabular}

\begin{tabular}{llllll}
\hline$N=141$ & Not readmitted & $(\%)$ & Readmitted & $(\%)$ & $P$ value* \\
\hline Confidence at discharge & & & & & \\
High confidence $(\geq 7)$ & 103 & $(90.4)$ & 25 & $(92.6)$ & 1.0 \\
Low confidence $(<7)$ & 11 & $(9.6)$ & 2 & $(7.4)$ & \\
Confidence at discharge & & & & & \\
High confidence $(\geq 8)$ & 91 & $(79.8)$ & 15 & $(55.6)$ & $\mathbf{0 . 0 0 9}$ \\
Low confidence $(<8)$ & 23 & $(20.2)$ & 12 & $(44.4)$ & \\
\hline
\end{tabular}

*Chi square or Fisher's Exact; Bold signifies $p$ value $<0.05$ 
pilot found that patients frequently associated their family and social support system outside of the hospital with confidence managing their health. While health-system administrators may not be able to provide social networks as easily as a follow-up physician appointment, understanding patients' family or friend network could help systems flag those who need more attention.

As health systems continue to explore innovative practices to service patients at risk for readmission, implementing simple questionnaires may help flag patients, but identifying an appropriate cost-effective intervention to alleviate social support structures may still be a major challenge. Hospital administrators may consider other alternatives to capture patient-reported health confidence, but this approach was easily implemented by existing pharmacy operations staff. Implementing a financially sustainable process to capture self-reported patient confidence for all patients being discharged may be considered the first step toward a better patient-centered discharge and care transition process. Disseminating these preliminary findings, while limited in size and scope, may encourage other institutions to pilot similar low-cost programs at discharge and determine whether a patient-reported health confidence score could be helpful in better post-discharge outcomes.

Author Contributions TJM collected and analyzed data; manuscript writing and review. KN collected data; contributed to qualitative analysis and significant revisions to the manuscript.

\section{Compliance with ethical standards}

Funding This study was supported by an educational grant from Bristol Myers Squibb.

Conflicts of interest TJM has received funding for research unrelated to the study from ALK, Inc. and the Patient Centered Outcomes Research Institute, and has received consulting fees for advisory boards for Summit Therapeutics and Paratek Pharmaceuticals also unrelated to this study. $\mathrm{KN}$ has no conflicts of interests to disclose.

Open Access This article is distributed under the terms of the Creative Commons Attribution-NonCommercial 4.0 International License (http://creativecommons.org/licenses/by-nc/4.0/), which permits any noncommercial use, distribution, and reproduction in any medium, provided you give appropriate credit to the original author(s) and the source, provide a link to the Creative Commons license, and indicate if changes were made.

\section{References}

1. Hibbard JH, Greene J. What the evidence shows about patient activation: better health outcomes and care experiences; fewer data on costs. Health Aff. 2013;32:207-14. https://doi.org/10.1377/hltha ff.2012.1061.

2. Ho L, Haresch JW, Nunlist M, Schwarz A, Wasson JH. Improvement of patients' health confidence. JAmbul Care Manage. 2013;36:235-40. https://doi.org/10.1097/JAC.0b013e3182955af7.

3. J.H. Wasson, E.A. Coleman. Health confidence: a simple, essential measure for patient engagement and better practice. Fam Pract Manag (2014).

4. Martin AB, Hartman M, Washington B, Catlin A, National Health Expenditure Accounts Team. National health spending: faster growth in 2015 as coverage expands and utilization increases. Health Aff. 2015;36(2017):166-76. https://doi.org/10.1377/hltha ff.2016.1330.

5. Maliski SL, Kwan L, Krupski T, Fink A, Orecklin JR, Litwin MS. Confidence in the ability to communicate with physicians among low-income patients with prostate cancer. Urology. 2004;64:329 34. https://doi.org/10.1016/j.urology.2004.03.042.

6. Wolf MS, Davis TC, Osborn CY, Skripkauskas S, Bennett CL, Makoul G. Literacy, self-efficacy, and HIV medication adherence. Patient Educ Couns. 2007;65:253-60. https://doi.org/10.1016/j. pec.2006.08.006.

7. Corbin JM, Strauss A. Grounded theory research: procedures, canons, and evaluative criteria. Qual Sociol. 1990;13:3-21. https ://doi.org/10.1007/BF00988593.

8. Wasson JH, Johnson DJ, MacKenzie T. The impact of primary care patients' pain and emotional problems on their confidence with self-management. J Ambul Care Manage. 2008;31:120-7. https://doi.org/10.1097/01.JAC.0000314702.57665.a0.

9. T. Wu, C. Williams, K. Vranek, T.J. Mattingly. Using 340B drug discounts to provide a financially sustainable medication discharge service. Res Soc Adm Pharm (2018). https://doi.org/10.1016/j. sapharm.2018.03.065.

10. Health Resources \& Services Administration. 340B Drug Pricing Program (2018). https://www.hrsa.gov/opa/index.html. Accessed 11 Oct 2018.

11. Hasan O, Meltzer DO, Shaykevich SA, Bell CM, Kaboli PJ, Auerbach AD, Wetterneck TB, Arora VM, Zhang J, Schnipper JL. Hospital readmission in general medicine patients: a prediction model. J Gen Intern Med. 2010;25:211-9. https://doi.org/10.1007/ s11606-009-1196-1. 